\title{
Condiciones socioeconómicas y afectivas de jóvenes universitarias madres de familia
}

\author{
Diana-María González-Bedoya y Ana-María Molina-Osorio
}

\section{RESUMEN}

Se presentan resultados de la investigación sobre la experiencia de jóvenes universitarios de Psicología y Preescolar del Tecnológico de Antioquia que son madres/padres. Las condiciones socioeconómicas y afectivas, la feminización de la crianza y el sostén para la crianza, son hallazgos esenciales para el análisis de la deserción estudiantil, especialmente de las jóvenes madres y sus familias, en quienes se concentra la responsabilidad económica y afectiva de la crianza, un tema poco estudiado en Colombia. La metodología mixta permitió hacer diseño y pilotaje de encuesta que podrá aplicarse a toda la población estudiantil para intervenir integralmente y prevenir la deserción.

Palabras clave: familia, jóvenes, universitarias, maternar, crianza, deserción estudiantil, Colombia. 


\title{
Condições socioeconómicas e afetivas de jovens universitárias mães de família
}

\section{RESUMO}

Apresentam-se resultados da pesquisa sobre a experiência de jovens universitários de Psicologia e Préescolar do Tecnológico de Antioquia que são mães/pais. As condições socioeconómicas e afetivas, a feminização da criação e o sustento para a mesma, são descobertas essenciais para a análise do abandono estudantil, especialmente das jovens mães e suas famílias, nas quais se concentra a responsabilidade económica e afetiva da criação, um tema pouco estudado na Colômbia. A metodologia mista permitiu fazer desenho e disparo de enquete que poderá ser aplicado a toda a população estudantil para intervir integralmente e prevenir o abandono estudantil.

Palavras chave: família, jovens, universitárias, maternal, criação, abandono estudantil, Colômbia.

\section{Socio-economic and emotional conditions of young university mothers}

\begin{abstract}
The authors present the results of a research on the experience of young university students of Psychology and Preschool enrolled at the Tecnológico de Antioquia who are mothers/parents. Socioeconomic and affective conditions, the feminization of upbringing and the support for it are essential findings for the analysis of student desertion, especially of young mothers and their families, in whom the economic and affective responsibility for upbringing is concentrated, a subject little studied in Colombia. The mixed methodology made it possible to design and to monitor a survey that can be applied to the entire student population in order to intervene comprehensively and to prevent academic dropout.
\end{abstract}

Key words: family, youth, university students, maternity, upbringing, student dropout, Colombia. 


\section{Introducción}

El análisis que se presenta, es parte de los hallazgos de la investigación: Impacto socioafectivo y académico de la experiencia de paternar-maternar y estudiar. Proyecto piloto realizado con los estudiantes de I a $V$ semestre de Preescolar y Psicología de las sedes Itaguií, Copacabana y Robledo del Tecnológico de Antioquia 2016-2017, ${ }^{1}$ cuyo objetivo a largo plazo es comprender el impacto socioafectivo y académico que ha tenido en los/as estudiantes del Tecnológico de Antioquia (TA), Institución Universitaria (IU) (sedes Itagüí, Copacabana y Robledo) la experiencia de paternar y/o maternar; ${ }^{2}$ con el fin de proponer alternativas de intervención psicosocial y psicopedagógica que contribuyan a fortalecer el vínculo afectivo de los/as estudiantes con sus hijos/as, con su familia y con la IU, para disminuir la probabilidad de deserción estudiantil.

Es amplio el espectro de estudios que analizan las causas de la deserción, permanencia y culminación exitosa de estudios en educación superior que, por su aumento, es tema prioritario en las políticas de calidad educativa; sin embargo, dichos estudios, analizan la maternidad/paternidad de los universitarios como una variable entre muchas (González y Molina, 2016). Pero las investigaciones realizadas en América Latina que abordan este fenómeno corroboran que la maternidad/paternidad, a temprana edad, es un fenómeno social que se hace endémico en la región (Barrero et al., 2015; Piratoba y Barbosa
2013; Estupiñán y Vela, 2012; Estupiñán y Rodríguez, 2009; MEN, 2009).

Las condiciones socioeconómicas de una región y las políticas administrativas, determinan las oportunidades que se ofrecen a los/as jóvenes e influyen notablemente en la calidad educativa, en el rendimiento académico y en la permanencia (González y Molina, 2016: 2 315). Específicamente, las familias de Medellín enfrentan grandes problemáticas como el acceso, la calidad y la pertinencia de la educación; pocas oportunidades de empleo, el aumento del subempleo o empleo informal; el conflicto social urbano, entre otros, que les imposibilitan cumplir cabalmente su función de cuidado y protección, y el goce efectivo de sus derechos. ${ }^{3}$

Las instituciones de educación superior (IES) tienen el compromiso de educar con calidad, garantizar la permanencia y culminación exitosa de todos sus estudiantes y en el TA-IU, casi el 99\% pertenecen a los estratos económicos ${ }^{4} 1,2$ y 3 , por tanto, requieren intervenciones integrales para garantizar sus derechos.

Para la Fase I se plantearon los siguientes objetivos: 1) hacer una caracterización de las condiciones socioeconómicas, familiares y educativas de los/as estudiantes de I a V semestre de Psicología y Preescolar de las sedes Itagüí, Copacabana y Robledo del TA-IU que son padres y madres; 2) describir la dinámica relacional entre el/la estudiante, su hijo/a

\footnotetext{
${ }^{1}$ Aprobado por el CODEI en Acta no. 2 del 14 de marzo del 2016. Vinculado al Grupo de investigación Observatos. Facultad de Educación y Ciencias Sociales.

${ }^{2}$ Maternar y Paternar alude a las prácticas de cuidado y protección que implementan cotidianamente las mujeres y los hombres con sus hijos e hijas para garantizar no solo su supervivencia, sino el proceso de socialización. Estos cuidados se denominan prácticas de crianza y son prodigados por aquellas personas que establecen un vínculo afectivo con estos niños y niñas especialmente en la primera infancia y la niñez temprana. En casi todas las culturas se espera que los padres biológicos sean los encargados de establecer este vínculo, pero, en las complejas relaciones vinculares, esta función puede cumplirla una persona diferente, la única condición es que establezca un fuerte vínculo de apego con el niño/a y asuma estas funciones. La diferencia entre el paternar y maternar estaría ligada a las representaciones sociales y culturales sobre la maternidad y la paternidad.

${ }^{3}$ Ver informes de El Colombiano: http://www.elcolombiano.com/antioquia/seguridad/cuatro-conflictos-afectan-la-vida-en-medellinAJ4579626> y El Tiempo: http://www.eltiempo.com/colombia/medellin/la-salud-lo-que-mas-se-afecta-debido-a-la-mala-calidad-delaire-64590.

4 "La estratificación socioeconómica es una clasificación en estratos de los inmuebles residenciales que deben recibir servicios públicos. Se realiza principalmente para cobrar de manera diferencial por estratos los servicios públicos domiciliarios permitiendo asignar subsidios y cobrar contribuciones en esta área". DANE 2019 https://www.dane.gov.co/index.php/servicios-al-ciudadano/serviciosinformacion/estratificacion-socioeconomica.
} 
y su familia, y 3) identificar las dificultades y oportunidades que afrontan las/as estudiantes para asumir sus responsabilidades como padres/madres y estudiantes universitarios.

\section{Metodología}

El paradigma de investigación fue comprensivo con enfoque mixto: hermenéutico descriptivo de las prácticas sociales de los/as estudiantes padres/madres, y se pretendió ir más allá de la descripción de los datos para proponer categorías de análisis emergentes.

La población objeto de estudio fueron 1750 estudiantes de I a V semestre de Preescolar y Psicología de las sedes Itagüí, Copacabana y Robledo del TAIU, matriculados entre julio de 2016 y julio de 2017 (ver gráfico 1).

\section{Grafico 1. Número de estudiantes matriculados por programa (junio 2016 a junio 2017)}

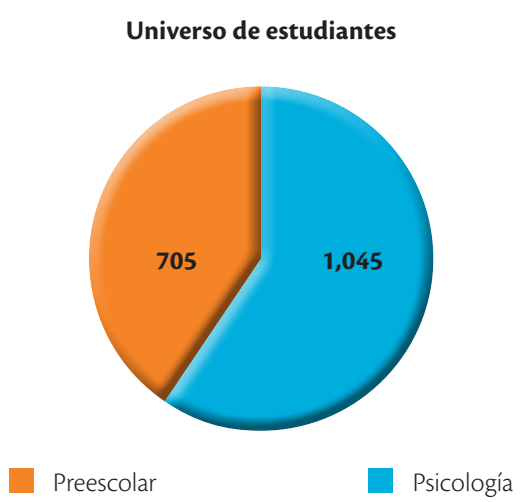

Fuente: elaboración propia.

\section{Tipo de muestreo}

Los casos se obtuvieron a través de correos masivos, voz a voz, visita al aula y la técnica bola de nieve (Galeano, 2007). En total se encontraron 65 casos: 63 mujeres y 3 hombres. Esta muestra no es representativa en relación con el total de la población referenciada, pero se constituye en la muestra significativa, en tanto cumplían la condición de ser estudiantes y padres/madres, convirtiéndose en la unidad de análisis, con quienes se implementó el pilotaje de la encuesta sociodemográfica y afectiva.

\section{Técnicas e instrumentos aplicados}

Diseño, pilotaje y validación de la encuesta para conocer las condiciones socioeconómicas y familiares de los/as estudiantes de I a V semestre de Preescolar

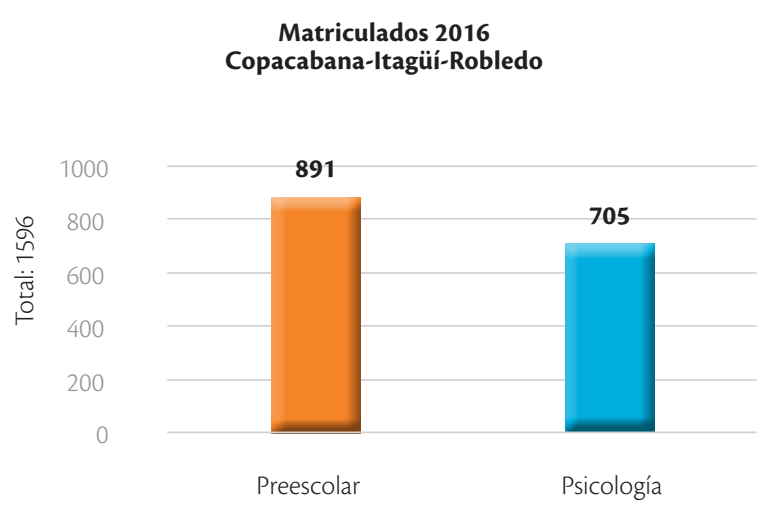

y Psicología de las sedes Itagüí, Copacabana y Robledo que eran padres/madres de familia. El instrumento fue sometido a fiabilidad a través valoración de expertos, ${ }^{5}$ para hacer los ajustes necesarios al instrumento.

Entrevistas semiestructuradas en profundidad a los/as estudiantes padres/madres de Psicología y Preescolar que respondieron la encuesta y accedieron voluntariamente a participar. El objetivo fue conocer en profundidad sus contextos universitario y familiar, sus percepciones acerca del apoyo que les ofrece su familia, los problemas que enfrentan en su proceso académico, las expectativas propias y las familiares, entre otros. Este proceso comenzó en junio de 2016 y se terminó en marzo del 2017, pues se implementaron en los meses de actividad académica.

\footnotetext{
${ }^{5}$ Expertos asesores en estadísticas e Ingeniería de Sistemas.
} 
Todas las entrevistas se realizaron dentro de la institución. En total fueron 15 entrevistas (14 mujeres y 1 hombre).

Grupo focal: a partir de las entrevistas grupales realizadas con estudiantes encuestados, para profundizar los sentidos encontrados en las entrevistas y observaciones, e indagar las estrategias que la IU podría implementar para apoyarlos en su proceso de maternar/paternar y estudiar, se realizaron cinco grupos focales: dos en Itagüí, dos en Robledo y uno en Copacabana.

Observación no participante: ésta se realizó hacia los/as estudiantes de cualquier programa que llevaran a sus hijos de primera infancia en horario de clases al TA-IU sede Robledo. El objetivo era observar la interacción del/la joven con su hijo/a, con los otros estudiantes y los docentes. Se hicieron en total 10 observaciones de entre 15 y 20 minutos cada una.

\section{Análisis de los datos}

El pilotaje de la encuesta permitió evidenciar falencias y bondades del instrumento y hacer ajustes a las preguntas para valorar cuales de ellas pueden agregarse a la encuesta que hace el TA a todos los estudiantes que ingresan. De otro lado, los datos obtenidos con la encuesta permiten encontrar factores socioafectivos que pueden ser un riesgo hacia la deserción y protectores para la permanencia de los/as estudiantes en la universidad.

El análisis hermenéutico de los datos obtenidos en las entrevistas y grupos focales permitió construir unidades de sentido sobre el significado que ha tenido para ellos esta experiencia de ser estudiantes y padres/madres de familia. Ello se logró haciendo triangulación entre las distintas técnicas implementadas (entrevista, encuesta, observación), entre los datos sociodemográficos y los sentidos aportados por los/as estudiantes y el análisis de las investigadoras.

Se analizaron una por una las transcripciones de las entrevistas y grupos focales, las descripciones de las observaciones haciendo codificación in vivo de lo s textos, codificación axial e identificación de tendencias que permitieron encontrar los sentidos sobre: la dinámica relacional entre el/la estudiante, su hijo/a y su familia, y las dificultades y oportunidades que afrontan para cumplir con ese nuevo rol de madres/ padres y estudiantes universitarios.

\section{Consideraciones éticas}

Para las entrevistas y grupos focales se ofrecieron espacios adecuados, seguros y tranquilos que garantizaran la confianza y la confidencialidad. Se preservó la integridad física y emocional con el anonimato de los estudiantes que participaron. Se les explicó detalladamente el proceso a seguir, los objetivos y metodología de los encuentros, y se obtuvo el consentimiento informado; los audios fueron transcritos literalmente, pero se omitieron nombres personales, institucionales, lugares o cualquier otro dato que pudiera identificar al/la participante.

\section{Resultados de la encuesta}

\section{Contexto socioeconómico y afectivo de los/as estudiantes que son padres/madres}

El número total de estudiantes en ambos programas que son padres/madres fue de 65; de ellos 32 pertenecen a Preescolar y 33 a Psicología (ver gráfico 2).

En cuanto a la proporción por género, en el total de casos identificados se encuentra que el 95.4\% son mujeres y el $4.6 \%$ son hombres dado que se encontraron sólo tres padres de familia. Uno de ellos convive con su pareja y su hijo, los otros dos continúan viviendo con su familia de origen, aunque los tres asumen el cuidado y/o provisión económica de sus hijos total o parcialmente, contando con el apoyo de sus propias familias.

La indagación sobre el número de hijos de cada estudiante arrojó los siguientes resultados: 55 estudiantes (85\%) tienen un solo hijo; por su parte, cinco estudiantes $(8 \%)$ tienen dos hijos y cuatro $(6 \%)$ tienen 3 hijos, éstas conviven con su pareja en unión libre o matrimonio. 
El estado civil que prevalece es soltero/a (30), le siguen en su orden, unión libre (23) y casados (9) (ver gráfico 3)

Cuando se hace la sumatoria entre quienes habitan en casa propia (14), más los que viven en vivienda familiar (14), da un total de 28 estudiantes que no pagan alquiler, es decir, el 43\%. Los que dicen vivir en casa propia corresponden al $21.5 \%$, y el $53 \%$ deben pagar alquiler. En relación con el estrato, se encuentra que $68 \%$ pertenecen al estrato $1.3 \%$ al estrato 2, y $8 \%$ al estrato 3 , que son los sectores objetivo de la institución, y que en total equivalen al $79 \%$.

\section{Gráfico 2. Número de estudiantes por programa que son padres/madres}

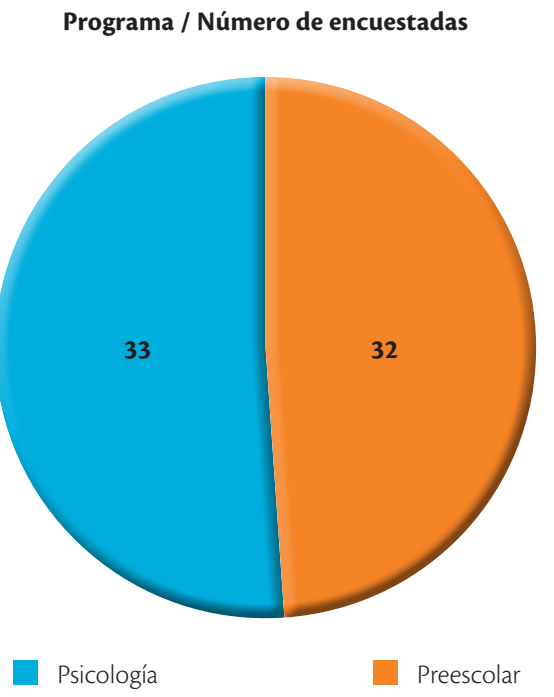

\section{Gráfico 3. Relación entre género y tipo de unión}

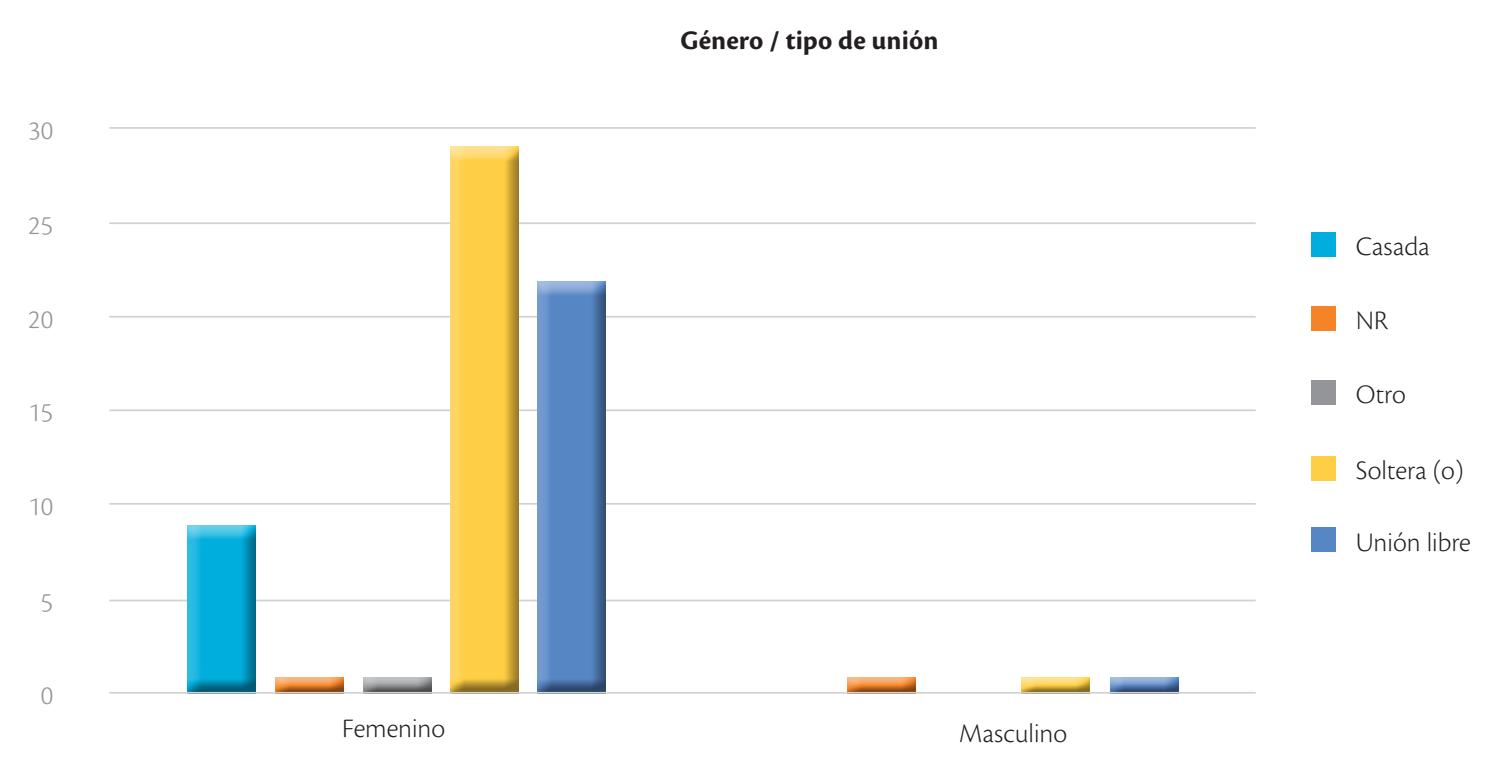


De otro lado, el 28\% de los estudiantes encuestados realizan alguna actividad laboral por horas/ día/semana, generalmente con contratos informales o por obra contratada. Los sectores y actividades en los cuales se desempeñan son meseros, ventas o call center. Quienes dicen tener contrato laboral (6\%), generalmente es por tiempos definidos o temporales (5\%); también están aquellos que trabajan independientes, generalmente en ventas por catálogo.

La pregunta sobre las ayudas económicas es sustancial para este proyecto, porque es una estrategia que mejora la calidad de vida y eleva las condiciones académicas de los/as estudiantes. Se encontró que el $40 \%$ de los encuestados recibe ayuda económica para el pago del semestre, transporte o alimentación de alguna entidad pública o privada como: Presupuesto Participativo, Jóvenes en Acción, Familias en Acción, entre otras.

Del total de estudiantes encuestados, el 57\% realizó estudios previos a su formación profesional, en instituciones públicas o privadas del nivel técnico, tecnológico o profesional. Las áreas de formación son diversas y no tienen relación directa con el programa que cursan actualmente, Psicología o Preescolar.

La cancelación de materias y/o suspensión del semestre es una alerta para la deserción, a este respecto se encontró que nueve estudiantes habían cancelado materias alguna vez durante la carrera, especialmente de ciencias básicas (estadística, matemáticas, ingles), porque la consideraron difícil, por la metodología del docente o por problemas económicos. Tres estudiantes admitien que suspendieron una vez sus estudios por la maternidad, aunque reingresaron.

El 78\% de los/as estudiantes perciben que su rendimiento académico es bueno, sólo el 9\% lo considera excelente, lo cual puede estar relacionado con el hecho de que reciben subsidio económico de alguna entidad, lo que les exige mantener un buen rendimiento académico o un promedio mínimo. De igual manera, como se verá en las entrevistas, la experiencia de maternidad para estas jóvenes se convierte en un aliciente para asumir con mayor responsabilidad otras dimensiones de su vida.

Un asunto curioso que se derivó de la preguntas sobre el tiempo dedicado al estudio, fue la dificultad para diferenciar entre el tiempo dedicado al estudio de manera individual ${ }^{6} \mathrm{y}$ las horas presenciales en clase. Para ellos/as, el tiempo dedicado al estudio es la sumatoria de todas las horas que pasan dentro de la universidad haciendo diferentes actividades entre lúdicas, deportivas, academicas, de ocio bien sea recibiendo clase, estudiando o departiendo con sus amigos/as.

Es común que los/as estudiantes convivan con otros familiares o con amigos, reuniendo varios hogares en la misma vivienda. El 42\% de los/as estudiantes conviven con su familia de origen, es decir, son de familia extensa, porque incluye a sus abuelos, padres, compañero e hijos; el 32\% son familias nucleares, conformadas por la estudiante, su compañero y sus hijos; el 12\% son ampliadas, porque incluyen otros familiares como tíos y primos; y sólo el 8\% son monoparentales de jefatura femenina, en las cuales la estudiante está totalmente a cargo de la crianza y cuidado de su hijo/a.

Las abuelas son quienes más las apoyan (34\%); esto incluye madres, abuelas y suegras de las estudiantes. Le siguen en su orden, ellas mismas en $23 \%$; las instituciones (guarderías públicas o privadas) representan un $11 \%$; también, aparecen los padres de sus hijos, sea que convivan con ellos o no, en cuatro casos, que equivalen a un $6 \%$; y finalmente, aparecen en menor proporción sus vecinas o amigas (ver gráfico 4).

\footnotetext{
${ }^{6}$ Lo que en el pensum académico aparece como tiempo de trabajo presencial/tiempo de trabajo autónomo.
} 


\section{Gráfico 4. Persona que cuida al hijo/a}

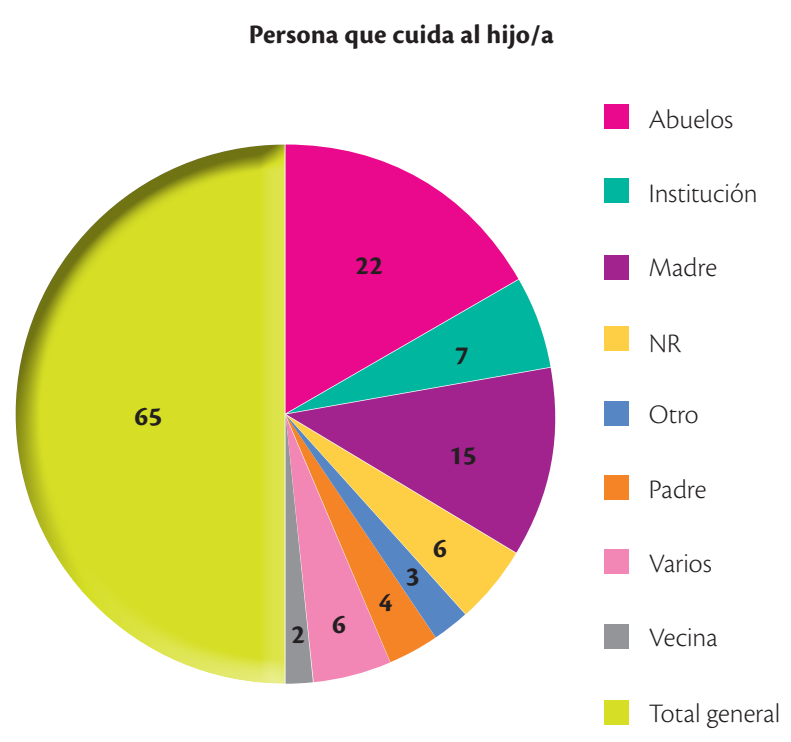

Fuente: elaboración propia.

\section{El tiempo de la universidad y la crianza}

En el ítem tiempo dedicado a estudiar y el que dedican a sus hijos, se encontró que el 34\% permanecen 4 horas/día y 31\% 6 horas/día dentro de la universidad. Si a esto se suma el tiempo que tardan en trasladarse de la casa a la universidad y vicever$\mathrm{sa}^{7}$ significa que $65 \%$ de estas jóvenes madres pasan de 6 a 8 horas sin tener contacto con sus hijos/as. Además, cuando llegan a sus hogares y comparten cara a cara con sus hijos, deben dedicar tiempo para preparar clases y hacer oficios domésticos.

En menor medida, pero de gran impacto sobre el acompañamiento que estas jóvenes madres dan a sus hijos, se encuentra que el 18\% permanece ocho horas fuera, más dos horas de transporte, lo que significa que ellas sólo ven a sus hijos en las noches y los fines de semana, por tanto sus hijos son criados por las abuelas y bisabuelas.

La relación del tiempo dedicado al estudio (dentro y fuera de la universidad) y las horas que pueden compartir con sus hijos, se observa que 22 de las encuestadas $(34 \%)$ dedican entre 5 y 8 horas diarias. Hay una coincidencia con la respuesta del ítem siguiente, frente a la satisfacción que ellas sienten por el tiempo dedicado a sus hijos; el 57\% siente que no es suficiente.

\section{Los hallazgos desde la mirada comprensiva Del embarazo no deseado a la maternidad/ paternidad asumida}

A pesar de que la maternidad fue para estas jóvenes un suceso no programado, se convirtió en una responsabilidad asumida. La idea de que los hijos verdaderamente deseados "son los planeados", y el embarazo inesperado, especialmente a temprana edad, es "un fracaso" - del método anticonceptivo, del cuidado, del proyecto de vida - no hace parte de la representación que ellas tienen de la maternidad. Tal vez porque la mayoría de las participantes ya habían superado el impacto de la noticia y sus hijos/as

\footnotetext{
${ }^{7}$ Más o menos dos horas en transporte publico uniendo ambos trayectos.
} 
ya eran parte de su familia, ninguna denigró esta experiencia. También es posible que el hecho de que todas provienen de sectores populares en los cuales esta situación es muy común y se asumen los hijos como "un regalo de Dios", sea por lo que no hacen de este acontecimiento una tragedia; posiblemente, también se deba a que el embarazo fue una consecuencia natural de tener una pareja, estar enamoradas y vivir su sexualidad, aunque lleven poco tiempo de relación.

Esto no quiere decir que el embarazo y la maternidad no cambien su vida, por el contrario, todas admiten que éste produjo cambios en sus rutinas de la vida personal, familiar, académica, social y laboral, especialmente cuando se da a temprana edad (14 a 16 años). El embarazo no planeado cambia su ritmo de vida y las actividades de diversión los fines de semana, propias de la juventud.

\section{(...) al principio es muy duro porque como uno es tan joven y estudiando y uno está acostumbrado a salir los fines de semana, entonces es una rutina que ya se le acaba, ya uno tiene atrás responsabilidades más grandes, pero uno continúa. (Ent-GO-Pre-I). ${ }^{8}$}

El embarazo temprano siempre genera tensiones en la vida individual y colectiva de las/los jóvenes y sus familias. De cómo resuelvan dichas tensiones, asimilan el embarazo y la llegada del nuevo integrante, dependerá el avance o retroceso en el desarrollo individual y del grupo familiar. Todas coinciden en una cosa: el apoyo y comprensión de sus familias es la fuerza que las motiva para continuar su proyecto vital, aunque esta situación no sea fácil de asimilar, pues el embarazo adolescente siempre es inesperado y genera reflexiones en las familias que pueden ser favorables o no para la acogida de otro miembro, y fortalecer los vínculos entre todos.
Sí, mi mamá y mis hermanitos recibieron bien la noticia del embarazo porque sabían que el papá de la niña era un muchacho responsable, lo conocían. Mi papá no la recibió tan bien porque dijo que yo le había dañado la vida, que lo había matado en vida. La familia de él [pareja] no lo recibió tan bien, la mamá de él no y ahí empezaron los problemas míos con él. (Ent-JV-Pree-R).

Asumir con responsabilidad las tareas de la crianza, les implica renunciar al tiempo de ocio y a las actividades recreativas propias de su edad, todas reconocen que "salen poco", no solo porque su hijo/a se convierte en una prioridad, sino porque sus energías están concentradas en la crianza y el estudio. Estas dos responsabilidades juntas, han generado una resignificación de la vida, es como si la maternidad les hiciera dar un salto hacia procesos de madurez emocional y psíquica que produce un descentramiento de sí, y las pone en el lugar de cuidar de otros; del placer inmediato a proyectar sus acciones cotidianas en función del cumplimento de una meta a largo plazo; de no tener ningún plan de vida, a construir uno con su hijo/a.

Mi hija me hizo sentar cabeza, porque me ayudó a sentar cabeza, pues a pensar en mí, en grande, en mis sueños, que es lo que quiero, en el futuro que quiero; antes no era dedicada al estudio, ahora sí. (Ent-LCF-Pree-I).

Aunque tener un hijo no es vivido por estas jóvenes como un fracaso, el momento en el que llega puede ser frustrante, porque se está proyectando hacia el mundo laboral y profesional. De igual manera, es posible que las expectativas de sus padres y esa sensación de frustración influya en la manera como algunas jóvenes se relacionan con sus hijos y con el padre de éstos.

\footnotetext{
${ }^{8}$ Los relatos de los/as estudiantes se referencian con las siglas correspondientes a la técnica (Ent: entrevista; GF: Grupo Focal; Obs: Observación). Letras codificadas para distinguir a los/as participantes y el programa al cual están inscritos: Pre: Preescolar Psic: Psicología. Al final la inicial de la sede R, I y C.
} 


\section{Sostén para la crianza}

Como se observa en los resultados de la encuesta, todas las jóvenes del estudio han recibido algún apoyo para el cuidado y crianza de sus hijos/as. Esta red de apoyo ha sido fundamental para que la joven madre fortalezca el vínculo con su hijo/a y permanezca en la universidad. Aún falta la presencia activa de la universidad, institución universitaria, pues aunque ofrece ayudas económicas y/o alimentarias, estas acciones no están intencionadas específicamente hacia las estudiantes que son madres, sino hacia la población estudiantil en general, por sus condiciones de vulnerabilidad, como lo evidencia la encuesta.

\section{La familia de origen: de padres a abuelos/as}

Dado que la mayoría de estas jóvenes fueron madres adolescentes, su familia de origen se encuentra en etapa adolescente y cada uno de sus integrantes tiene su propio proyecto de vida, por tanto, no pueden contar con los hermanos, pero sí con sus padres para la crianza de su hijos/as. El apoyo familiar se da especialmente de las abuelas en el cuidado de sus nietos. El vínculo afectivo se extiende hacia los nietos/as y en muchos casos incluye a la pareja de la joven. En todo caso, la familia de origen de la joven madre es la que se encarga de cubrir todas sus necesidades: la manutención económica de la joven y su hijo y el apoyo moral y afectivo que tanto requieren para cumplir sus roles.

Entre todos me pagan la universidad, esta vez mi mamá hizo el esfuerzo, ya el otro mi abuela y mi tía me dijeron que me iban a colaborar (Ent-LCF-Pre-I).

Mi mamá es la que más me ayuda para cuidarla según lo que veo con él, la mayor responsabilidad es mía y de mis papás (Ent-EL-Pre-I).

En lo moral es invaluable, en tanto acogen a las jóvenes madres y les impulsan a asumir responsablemente su maternidad y sus estudios; en lo económico, asumen además de todos los gastos de la joven estudiante, los de sus hijos/as.
El hecho de que la familia estimule e incluso "presione" a la joven para que siga estudiando, muestra un cambio en las representaciones sobre el valor social del estudio, como una alternativa legal, legítima y valiosa para "salir adelante". En ello están puestos además las esperanzas de las familias para contar con una profesional, lo que se revela, además, es que concentren sus esfuerzos en las mujeres estudiantes. Es como si el resto de la familia pusiera todo su empeño para que ellas cumplan ese "sueño familiar" que los demás no pueden: "Ser Profesional". Un asunto que muestra el cambio en las tradiciones con perspectiva de género, favoreciendo más a las mujeres.

la mamá de él [esposo] me apoyó mucho en el colegio porque yo no me salí de estudiar, entonces mientras yo estudiaba la mamá del papá del niño me cuidaba porque en esos momentos mi mamá estaba trabajando (Ent-GO-Pre-I).

En un país en el cual la educación es un negocio $\mathrm{y}$ acceder al nivel universitario es un privilegio, vale la pena rescatar las respuestas de las familias que se comprometen para que ellas puedan alcanzar lo que muchos jóvenes no lograrán.

\section{Los otros que ayudan}

Aunque en menor medida, aparecen las amigas, compañeras de universidad o del trabajo, amplían su red de apoyo en el cuidado de sus hijos/as, especialmente cuando deben asistir a clases. Estos apoyos son provisionales por lo que pueden ser varias personas, dependiendo de su disponibilidad. Esta estrategia podría tener riesgos o cierta inestabilidad paro los/as niños/as, pero les permite contar con los recursos que tienen a su alrededor para cuidar a sus hijos, además se convierte en una mediación en la socialización que amplía el espectro de agentes socializadores para ellos mismos (González, 2017). 
todos los días, depende de quién me la vaya a cuidar (Ent-LCF-Pre-I).

alquilé una pieza donde una amiga y empezó a cuidármelo la hermana de la señora de la guardería, me lo cuidaban la mamá de mis amigas y yo veía que el niño estaba bien con ellas (Ent-KM-Psic-G).

Otra ayuda que apareció es la institución educativa de primera infancia9 "Cuando sale del preescolar, lo cuida la abuela, ella lo lleva, lo trae" (Ent-KMPsic-G). Estos lugares, además de tener las condiciones adecuadas, son un espacio de protección que amplía la socialización de los niños/as, les permite tomar un poco de distancia de sus abuelas, y les da a ellas un tiempo de descanso; además, destensiona a las jóvenes madres para que puedan dedicarse a sus estudios, aliviana a madres y abuelas de la responsabilidad del cuidado y crianza, así sea por unas horas, y favorece el desarrollo integral de los niños/as porque están al cuidado de personal especializado.

\section{El padre de mi hijo/a}

El apoyo emocional, afectivo y material del padre de sus hijos durante el embarazo y posterior al nacimiento, es fundamental para fortalecer el vínculo de la joven madre con su hijo. Esto pudo observarse especialmente en aquellos que continuaron siendo pareja, independiente si vivían juntos o no:

el papá responde del todo por ella [la hija]. Sí, él es muy responsable en ese sentido, nunca le ha faltado con los pañales, o sea, él siempre nos apoya mucho, respetamos también la opinión de cada uno, y sí (Ent-LCF-Pre-I).

cuando nació el papa era ahí siempre, siempre, o sea se creó el vínculo desde pequeña, desde el vientre él estuvo ahí, porque cuando nosotros la concebimos, estábamos juntos, nos queríamos mucho, estábamos como en la flor de la relación (Ent-ET-PS-R).

La frase "Responde por el hijo", significa no sólo darles el apellido a los hijos. Ser "un padre responsable" remite en primera instancia, al hombre que asume la manutención, es decir, los gastos diarios de su cuidado; pero tambien se asocia con acompañar la crianza de su hijo y preocuparse por la joven madre:

(...) estar en embarazo es (silencio) ¡de verdad que uno se queda sin palabras en serio! Recibí el apoyo de él, no me dejó sola, me acompañaba en todo: en los controles, cómo yo me sentía, en la alimentación.

Ha sido un buen compañero (Ent-LGF-Pree-I).

Estas jóvenes relatan que los padres de sus hijos/as, asumen su función de padres y esposos, no sólo dedicando tiempo a sus hijos/as, sino también a ellas, incluso cuando deciden continuar su proyecto sin convivencia.

\footnotetext{
él a veces cuando yo no tengo porque pues mi mamá me da lo suficiente pa la semana y por decir no me alcanzó me tocó gastarme la plata de los pasajes en trabajos, fotocopias entonces él [esposo] hay veces me ayuda también con los pasajes [...] Él le da las cositas al niño, los pañales, la ropita $[\ldots]$ el niño a veces se queda con el papá (Ent-GO-Pre-I).
}

Pero cuando la decisión es no seguir como pareja, rápidamente es la joven madre y su familia de origen quienes asumen la manutención, cuidado y crianza del niño/a. En estos casos, le corresponde al joven reivindicar su lugar como padre y hacer todo lo posible por mantener el vínculo con su hijo/a más allá de la manutención: "como él [esposo] llega a veces muy tarde del trabajo, llega cansado [...] que él se pone a cargarla, no, me toca a mí” (Ent-LCF-Pre-I).

\footnotetext{
${ }^{9}$ En la modalidad de guarderías, Jardines Infantiles o Centros de Desarrollo Infantil.
} 
De todas maneras, la joven madre y su familia pueden favorecer o entorpecer este vínculo paternofilial en tanto respeten la imagen del padre frente a su hijo/a, estimulen y exijan el encuentro entre ambos y permitan la relación con la familia de origen del joven padre.

Finalmente, se encuentra el apoyo de la familia paterna. Aunque para algunas es una carga inesperada "una boca más para alimentar" que se une al presupuesto familiar; otras lo toman de manera natural y se ocupan de los gastos que implica la crianza, bien sea en especie, dando a la madre insumos semanales como pañales, leche o algún dinero para su nieto/a; y otras familias llegan incluso a comprometerse a tal punto con el cuidado de la joven madre, que la incorporan a la familia como una hija más.

\section{Discusión}

\section{La deserción estudiantil: un indicador de fracaso que involucra la escuela, la familia y la sociedad}

Los últimos resultados en las pruebas Saber Pro confirman que Colombia está lejos de alcanzar las metas de calidad educativa en todos los niveles, a pesar de los esfuerzos que se han hecho por mejorarla en términos de formación de los docentes, la ampliación de cobertura y los espacios locativos, intentando cumplir los estándares internacionales; así lo ratifica el Ministerio de Educación Nacional (MEN, 2013), pues la tasa de deserción por cohorte, es decir, el número de estudiantes que desertan de cada 100 que ingresan a algún programa universitario, es de $45.3 \%$. Cifra muy parecida a México y Argentina con $42 \%$ y $43 \%$ respectivamente; y menor que Venezuela y Chile cuya deserción es de $52 \%$ y $54 \%$ y Costa Rica con $62 \%$.

Lo que enuncian estas cifras son problemas de fondo en la concepción de los modelos educativos que apuntan al crecimiento en las tasas de escolaridad, más que en la calidad, en la falta de políticas reales de inversión en la educación con visión de futuro, y en los numerosos estudios que se quedan en diagnóstico o plantean muy buenas teorías que no se materializan, porque las políticas nacionales siguen considerando la educación en competencias para la inserción laboral, y no en la formación para el desarrollo humano. Según el MEN (2013: 2), la deserción tiene consecuencias no sólo económicas, sino sociales, que se reflejan en la pérdida de recursos públicos y privados, pero sobre todo "en la pérdida del proyecto de vida de los jóvenes que apostaron a la educación superior y que constituyen una apuesta de país por la equidad".

Las discusiones teóricas sobre la mala calidad de la educación reconocen varias causas; según Gaviria (2002) "se divide en dos grandes grupos: quienes enfatizan en los recursos y quienes enfatizan en los incentivos a los docentes y los sistemas de rendición de cuentas" (citado en la Encuesta Nacional de Demografia y Salud ENDS-Profamilia, 2011: 21). Según el experto, en Colombia ambas dimensiones son importantes, porque en muchas regiones los recursos invertidos en la dotación física de las escuelas y colegios han sido insuficientes y son inexistentes; de otro lado, si bien se han hecho incentivos a los docentes, esto no ha repercutido en su buen desempeño o en elevar el nivel aprendizaje de los alumnos: "En Colombia, por ejemplo, la posición en el escalafón o los años de educación de los maestros no guardan ninguna relación con el desempeño de los estudiantes en pruebas estandarizadas, es decir, la remuneración y el ascenso en el escalafón nada tienen que ver con la calidad de la enseñanza impartida" (Gaviria, 2002, citado en Profamilia, 2011: 21).

Por su parte, Serna (2015, citado en González y Molina, 2016: 16) hace una reflexión sobre las causas reales y contextuales de los vacíos que tiene la educación en Colombia, y por qué no ha dado buenos resultados; además, considera que una educación de calidad para las nuevas generaciones, debería tener en cuenta las particularidades del contexto social, cultural, y sobre todo de la particularidad de cada 
estudiante para desarrollar sus habilidades y ofrecer una experiencia emocional positiva, que evalué las capacidades individuales y la forma en que un estudiante aprende. Una educación con calidad debe recuperar el sentido humanista que tiene la educación desde su origen, para formar a ciudadanos y educar, incluyendo saberes en las técnicas, pero también aprendizajes morales, sociales, emocionales, espirituales y estéticos.

De otro lado, hay una queja permanente de los docentes de que los padres se comprometen poco en la educación de sus hijos, se aíslan de la escuela y sólo aparecen cuando son llamados obligatoriamente a asistir, o cuando su hijo está a punto de abandonar la escuela. Los docentes sienten que, de alguna manera, los padres "abandonan a sus hijos" y van relegando la socialización a la escuela para dedicarse a conseguir el sustento, en algunos casos, o por negligencia, aduciendo que la educación es responsabilidad de la escuela y el Estado, no de ellos.

\section{Cambios en las familias colombianas}

Las transformaciones en la dinámica y estructura de la familia, se han dado en parte por las condiciones socioeconómicas y educativas a las cuales tienen acceso, también por las nuevas representaciones y prácticas sociales en torno a la maternidad/paternidad, la sexualidad/eroticidad, los roles de género, entre otros.

Estos cambios, que por lo demás son globales, los ratifican las estadísticas; sin embargo, estudios como el que se presenta, aportan a la comprensión de las dinámicas relacionales, especialmente en las familias jóvenes que empiezan a construir los/as estudiantes universitarios, que además son padres/madres de familia.

Según la ENDS (Profamilia, 2015a), en el último quinquenio aumentaron los hogares con una, dos, tres y cuatro personas, incluyendo los hijos y los padres o cuidadores, y cada vez disminuyen más las familias conformadas por cinco personas o más. Esta reducción ocurrió tanto en la zona urbana como en la rural.

Hay una tendencia a la reconfiguración de la familia, dando lugar a nuevas tramas vinculares de acuerdo no sólo con el número de personas que conviven bajo el mismo techo, los lazos de filiación o consanguinidad que han constituido, sino también por los lazos afectivos que establecen. En Colombia,

\begin{abstract}
$33.2 \%$ de los hogares está ocupado por familias nucleares biparentales; un $12.6 \%$ por nucleares monoparentales (falta el padre o la madre) y un $9.8 \%$ por parejas sin hijos; un $12.8 \%$ son familias extensas biparentales (pareja, hijos solteros, más otros parientes); $9.8 \%$ son extensas monoparentales (el jefe o la jefe sin cónyuge con los hijos solteros o casados y otros parientes); $2.9 \%$ pertenecen a parejas sin hijas/ os junto con otros parientes y en un $4.5 \%$ vive el jefe con otros parientes (ENDS, Profamilia, 2015a: 75).
\end{abstract}

En cuanto a la educación de las mujeres adolescentes y jóvenes de 13 a 24 años, el 59.5\% asiste actualmente a un establecimiento educativo (primaria, secundaria o universidad) y el $40.5 \%$ no estudia. Es decir, por cada tres mujeres que asisten, hay dos que no lo hacen. Lamentablemente, aumentaron los índices de inasistencia o abandono $(71.9 \%)$ en las mujeres que ya alcanzaron la educación secundaria completa, lo cual constituye un factor de gran riesgo para la pobreza pues no podrán aspirar a la universidad. Estas mujeres desertan por varias razones: $18.5 \%$ porque quedaron embarazadas; $7.3 \%$ no tienen dinero para pagar los estudios; $5.3 \%$ porque necesitan ganar dinero y otra razón para no continuar sus estudios es el matrimonio 8.9\% (Profamilia, 2015b).

En el censo 2010, "Los embarazos adolescentes, explicaban casi $10 \%$ de todos los casos de deserción escolar entre las mujeres menores de veinte años" (Gaviria, 2002, citado en Profamilia, 2011: 16); para el 2015 este porcentaje aumentó casi al doble. Datos 
relevantes, si se reconoce que ellas son la población cautiva para ingresar a la educación universitaria, pero quedan excluidas del sistema escolar con las graves consecuencias que ello acarrea en el círculo de la pobreza, dado que ya son madres o pronto lo serán, y no tendrán mejores alternativas laborales, pues ellas ni siquiera contemplan la posibilidad en sus planes de vida.

De otro lado, se ha encontrado que a medida que aumenta el nivel educativo de las mujeres éstas retrasan la edad para constituir una convivencia en pareja, "aunque en Colombia, las relaciones sexuales previas a la constitución de la primera unión son cada vez más comunes, la unión (legal o consensual) continúa siendo la institución predominante para la tenencia y crianza de los hijos e hijas. Entre más joven se unan las parejas, especialmente la mujer, mayor será el tiempo de exposición al riesgo de embarazo" (Profamilia, 2015b: 106).

En Colombia, la edad de la primera relación sexual en las mujeres es en promedio alrededor de los 17 años, edad en la cual deberían estar concentradas en su proyecto de vida personal y formándose para obtener algún título que les permita ganar en autonomía personal e independencia económica, "la fecundidad es mayor en la zona rural, en las regiones y departamentos menos desarrollados, en quintiles más bajos de riqueza y niveles más bajos de educación. Los diferenciales sociales más amplios se observan por nivel educativo" (Profamilia, 2015b: 298).

Según lo encontrado en ENDS (Profamilia, 2015b: 108), "la edad mediana a la primera unión aumenta a medida que mejoran las condiciones socioeconómicas, tanto en mujeres como en hombres: nivel de urbanización, nivel de desarrollo, nivel educativo, índice de riqueza”. De igual manera, entre más bajo el índice de riqueza al que pertenece la mujer, menor es la edad de la primera unión.

En acuerdo con Gaviria y Palau (2006b) es innegable que "la fecundidad adolescente afecta de manera adversa el desempeño socioeconómico de las madres y las condiciones de salud y nutrición de los niños, y constituye un obstáculo para la movilidad social y la superación de la pobreza" (citado en Profamilia, 2011: 16). Respecto al cuidado de los niños/ as, la ENDS 2010 encontró que:

\begin{abstract}
el $56 \%$ de los niños menores de 15 años vive con ambos padres, $32 \%$ solamente con la madre, 3\% solamente con el padre, y 7\% no vive con ninguno de los dos. De aquellos que viven sólo con la madre o sólo con el padre, 9 de cada 10 tienen el padre vivo o la madre viva. La proporción de niños que vive con ambos padres, o solamente con la madre, pero no con el padre, va disminuyendo a medida que aumenta la edad de los niños, 10-14 años (Profamilia, 2011: 34).
\end{abstract}

Las mujeres tienen que acudir a los abuelos, independientemente de su estado conyugal, para el cuidado de sus hijos/as, pero esa frecuencia es mayor cuando son solteras $(66.4 \%)$ y menor cuando viven con su pareja (36.9\%). Aparte de los abuelos, las mujeres solteras tienen que acudir a otros parientes (16.9\%), o llevar a los niños consigo (9.7\%) (Profamilia, 2015a: 185)

Los datos presentados, coinciden con lo planteado por Noriega (2015: 27): "El aumento de la esperanza de vida asociada a los avances médicos, nutricionales y de higiene ha dado lugar a una mayor funcionalidad de las personas mayores, lo que les permite contribuir en las tareas familiares, como puede ser el cuidado de los nietos o la atención de los hijos que ya se han casado y/o emancipado".

Un hallazgo importante de este estudio en cuanto a los embarazos y uniones a edades tempranas, es que el vínculo entre estas jóvenes y su familia de origen se fortalece, especialmente porque sus padres han cambiado sus concepciones de la maternidad temprana, en tanto estar embarazadas ya no significa ser expulsadas del hogar de origen; algunas inclusive relatan que sus madres las han apoyado como una manera de resistencia frente al rechazo que ellas 
mismas vivieron en su juventud cuando quedaron embarazadas; otras jóvenes aprovecharon esta condición para confrontar las creencias morales de sus padres, en términos de que estar embarazada no es sinónimo de pecado o degradación social.

\section{Maternar, paternar y estudiar: un reto y una oportunidad}

Ser joven universitario es una categoría asociada en el imaginario social, aunque implica un gran compromiso, tiempo y energía, porque estudiar es el camino para lograr un posicionamiento social a través de una profesión; ser padre/madre de familia en nuestra cultura es además de un rol de gran valor social, una aspiración para buena parte de la población como parte importante en su proyecto de vida; pero ser joven universitario y padre/madre de familia a la vez, son dos condiciones que pueden ser incompatibles, pues un hijo/a demanda cuidado, energía vital y recursos materiales que son inaplazables, especialmente para los padres que son los primeros responsables por ley y por vínculo afectivo; por esa razón, la maternidad/paternidad en los/as jóvenes universitarios se convierte en una "amenaza" para la permanencia y culminación de las carreras. De acuerdo con Estupiñán y Vela (2012), en el contexto universitario, el papel de madre y estudiante son roles que algunas mujeres deben asumir y compatibilizar su deseo de maternar con el logro de un título profesional.

Por un lado, se encuentra el deseo personal de estudiar una carrera que permita insertarse en el mundo laboral y responder a sus exigencias, y por otro, el rol de madre que se debe cumplir, de acuerdo con el estereotipo cultural y las expectativas sociales. De esta forma, la vivencia de la maternidad afecta, en mayor o menor grado, el proceso de aprendizaje y el desempeño como estudiante, e influye, por tanto, en las esferas académica, emocional y social (Estupiñán y Vela, 2012: 538). Pero también influye en esta experiencia la relación de la joven con su madre, siendo incluso determinante para potenciar o limitar "su capacidad y autopercepción para criar al recién nacido; determinándose que mientras mayor sea el apoyo recibido por parte de sus madres, mayor será su propia autoevaluación como madre" (De Vito, 2007, citado en Cimino, Durán, Herbage, Palma y Roa, 2014: 26).

Asimismo, De Vito (ibid.: 6) diferencia entre el apoyo intangible y el material, y da una mayor significación al primero, ya que ayudaría a formar una autopercepción más positiva de la maternidad. Los padres, ahora abuelos, empiezan a jugar un papel muy importante en la relación de la estudiante con su hijo, y son quienes le ofrecen apoyo en la crianza y en sus estudios, dado que la mayoría de las madres adolescentes continúan viviendo con sus padres después del nacimiento de su hijo y asume todo su cuidado, "en el momento actual, los abuelos y, sobre todo las abuelas, cumplen un papel esencial para la familia y para la sociedad, colaborando en el cuidado y educación de sus nietos y nietas" (García, Pérez y Martínez, 2014: 579).

Esta nueva condición maternal y paternal para los abuelos, genera cambios sustanciales en la dinámica familiar, en las responsabilidades económicas y de cuidado que plantean retos, riesgos y posibilidades para todos. Una situación que aumenta cada vez más como alternativa de apoyo afectivo y económico para esta joven madre es que "la familia adopta al nuevo bebé, asume todo su cuidado y apoya a la nueva madre" (Estupiñán y Vela, 2012: 545).

En los estudios realizados por De Vito (2010, citado en Cimino et al., 2014: 6) se identificó también al padre del recién nacido como "una fuente de apoyo secundario, ya que, a través de su colaboración en la crianza, puede llegar a ser significativo, como un apoyo emocional y tangible, mientras que, al encontrarse ausente, su relevancia disminuiría". La presencia del padre, además de generar bienestar psicológico a la madre, favorecería enormemente el vínculo padre-hijo/a. 
Además de la familia, las madres universitarias cuentan con una red de apoyo que en esa etapa de la vida la constituyen los amigos y los compañeros/as de estudio que les son de gran ayuda en lo académico y en lo emocional, pues como referencian Estupiñán y Rodríguez (2009) y Estupiñán y Vela (2012), el acompañamiento de otras estudiantes que ya han vivido situaciones similares, les dan confianza y conocimientos para la crianza y estrategias para afrontar situaciones adversas. Cuando las jóvenes madres no cuentan con el apoyo económico familiar implementan estrategias personales de ahorro, ingreso o disminución de gastos para mejorar su situación económica.

Según el estudio realizado en Colombia por Hernández y Orozco (2011) con madres que se encuentran estudiando carreras universitarias en la Universidad Libre de Barranquilla, se encuentra que esta condición les implica mayores obligaciones al tener que cumplir con ambos roles, que son de alta exigencia en esfuerzo físico y mental y dedicación de tiempo. Otra de las consecuencias psicológicas es un "quiebre en las expectativas que su entorno tenía para ella, siendo el embarazo un punto final a su proyecto de vida y un obstáculo a su desarrollo, generando sentimientos de tristeza, frustración, angustia y miedo" (Aracena, Benavente y Cameratti, 2002, citado en Cimino et al., 2014: 26). Pero una vez nace su hijo/a su rol se triplica, por lo cual se considera que estas mujeres asumen una triple condición: ser jóvenes, madres y estudiantes universitarias.

Esta situación puede hacerse conflictiva por el esfuerzo que implica responder a las exigencias de estudiar en la universidad y cumplir con el rol de madre (Cimino et al., 2014: 24); sin embargo, esta experiencia puede ser más o menos traumática "dependiendo del apoyo familiar que tengan las madres para continuar sus estudios, la orientación prenatal recibida, la participación en el proceso del padre del recién nacido, la responsabilidad, entre otros" (Szigethy y Ruíz, 2001, citado en Cimino et al., 2014:
25). Esta situación evidentemente enuncia una crisis para la estudiante y su familia, que puede ser temporal o volverse crónica, dependiendo de las fortalezas internas de la joven madre y de las redes de apoyo que, además de un apoyo material, la acompañen en su proceso de maternar y continuar sus estudios. Contar efectivamente con estos recursos será determinante en la visión que ella tenga de sí misma y de su capacidad para cumplir su rol maternal y ser exitosa en su carrera.

Las conclusiones del estudio realizado por Estupiñán y Vela (2012) toman en cuenta el ambiente físico, emocional y social de las estudiantes madres de familia, que incluye a la IU como espacio que puede ofrecer un apoyo fundamental para el logro de sus metas profesionales, no para la permanencia, sino en su condición juvenil y maternal. La aceptación de la familia y de la Institución Universitaria de su maternidad, es fundamental para que la joven madre asuma su nueva responsabilidad y pueda ver en esta experiencia una oportunidad de continuar su proyecto de vida.

\section{Conclusiones}

La comparación de los datos arrojados por la encuesta con los datos demográficos existentes en las bases de datos del TA-IU permitió concluir que, si bien la encuesta que se realiza a los estudiantes matriculados por primera vez es muy amplia, ésta obtenía información muy general de los estudiantes y carecía de los ítems que aporta la encuesta diseñada para este estudio. Cruzar la información de ambas encuestas sería de gran utilidad para que el TA-IU pueda hacer en primera instancia un tamizaje de los/las estudiantes padres/madres y posteriormente un seguimiento para evitar la deserción.

El hecho que la mayoría de los encuestados tenga un solo hijo puede tener relación, por un lado, con el hecho de que la mayoría no conviven en pareja, por tanto, sus familias les exigen cuidarse de un segundo embarazo; y también a que han tomado mayor 
conciencia de la responsabilidad que implica maternar y estudiar.

Sobre el estado civil, es de anotar, que aquellas que se nombran como solteras han continuado su relación con el padre de su hijo/a, aunque viven con sus respectivas familias de origen, lo que pone en evidencia un tipo de unión consensuada sin convivencia, nombrada en este estudio como Familia foven sin Convivencia.

La pregunta sobre si aportan a la economía familiar se hizo para contrastar la respuesta de algún vínculo laboral, los ingresos y el aporte económico que ellos/as hacen a sus familias, lo cual coincide con las entrevistas, pues efectivamente los/as estudiantes buscan diferentes alternativas para recibir ingreso, y de esta manera contribuir al cuidado de sus hijos/as o para su propia manutención.

Ser padres/madres, estudiar e incluso trabajar son tres obligaciones que requieren tiempo y esfuerzo, de ahí la importancia de conocer los efectos que ha tenido para el rendimiento académico, con variables como cancelación de materias o semestre, y el grado de dificultad que estas representan. Un dato importante es que los estudiantes cancelan especialmente aquellas materias que les generan dificultad de comprensión o presentan deficiencias, como son estadística e inglés. La suspensión del semestre en los tres casos encontrados se debió a la maternidad, lo que indica que este rol es un factor de alerta para la deserción femenina.

Un hallazgo inesperado de la encuesta que abre nuevas perspectivas de comprensión, es la representación que tienen los jóvenes del tiempo dedicado al estudio, en el cual incluyen el tiempo vivido dentro de la universidad. Aspecto que puede precisarse en la encuesta, pero en estudios posteriores permitiría ver de qué manera la universidad se convierte en espacio que acoge a los jóvenes y a sus hijos/as, más allá de impartir conocimientos.

La distribución del tiempo dedicado a estudiar (asistir a clase y estudiar en casa), y el que dedican a sus hijos, son factores importantes para valorar las funciones que estas deben cumplir en su triple condición ${ }^{10}$ de jovenes, madres y estudiantes universitarias. No obstante, la valoración es muy subjetiva, y no es posible medir en tiempo exacto, pues depende de las actividades que ellas comparten con sus hijos/as.

La percepción de insatisfacción frente al tiempo que ellas pueden dedicar a sus hijos/as puede tener repercusiones inmediatas en el estado de satisfacción general que estas jóvenes tienen como madres/estudiantes, y a largo plazo en el vínculo afectivo que ellas puedan establecer con sus hijos/as.

Estudiar implica para esta jóvenes dejar sus hijos/as al cuidado de otras personas, generalmente sus familias de origen. De ahí que saber quién cuida los hijos/as de los/as estudiantes resulta de gran valor para comprender los cambios o permanencias en las responsabilidades de la crianza y la presencia de otras instancias mediadoras en la socialización y cuidado de los niños y niñas.

Esta investigación tuvo perspectiva de género en tanto se intencionó la participación de hombres y mujeres que fueran padres/madres; sin embargo, los resultados evidencian que la mayoría de los casos fueron mujeres (62), lo cual ratifica, por un lado, la feminización de la crianza. Sólo se encontraron tres padres y ninguno estaba directamente involucrado con la crianza al momento del estudio. Por ello, el análisis final se concentra en las jóvenes madres. De otro lado, no debe olvidarse que los programas en los cuales se implementó el estudio (Preescolar y Psicología) tienen mayor demanda de población femenina.

\footnotetext{
${ }^{10}$ Se habla de "condición" porque se considera que son situaciones transitorias en la vida de las personas que les implica roles, funciones, prácticas y relaciones particulares. En ese sentido, ser joven se considera una condición, pues es una etapa de la trayectoria vital del ser humano que va cambiando; ser universitaria es otra condición que termina una vez obtienen su título y ser madre/padre, si bien alude a una relación que sólo termina con la muerte de alguno de los implicados en ese vínculo, las demandas de la crianza tambien tienen su tiempo limite a medida que los hijos/as van avanzando en su desarrollo.
} 
Aunque ellas nunca están totalmente solas en la crianza pues siempre aparecen personas o instituciones que sirven de sostén. Cuando el joven padre cuenta con empleo digno, también facilita la formalización de la unión libre y la convivencia independiente de la familia de origen. Estas prácticas de manutención también pueden leerse como actos de cuidado y soporte del padre hacia su nueva familia. Un rol asumido responsablemente, no sólo asignado u obligado por la legislación.

Toda la red social de apoyo, incluida la universidad, se convierte en un factor de predicción positiva para la permanencia de las jóvenes madres. El apoyo afectivo, económico y moral es fundamental para la crianza adecuada de sus hijos, para que ellas puedan continuar su proyecto de vida, lograr su autonomía identitaria, en compañía de su familia y sus hijos/as, y/o su pareja, es decir, la nueva familia elegida.

Si bien los hombres han cambiado sus prácticas de paternidad (las parejas y los padres de estas jóvenes), no están obligados a asumirla con las implicaciones de tiempo, responsabilidad económica y cuidados que exige la cotidianidad, como si lo hacen quienes viven con los hijos/as. Esta investigación ratifica que aún persiste la feminización en la crianza (González y Molina, 2016), porque son las mujeres (madres, abuelas, bisabuelas) quienes asumen esta responsabilidad; que la crianza sigue siendo una tarea asignada y asumida por las mujeres, además de la provisión económica porque muchas de estas abuelas son cabeza de hogar.

El pequeño número de casos encontrados (63), en proporción con el número total de estudiantes matriculados de ambos programas, confirma que la maternidad juvenil sigue siendo un riesgo no sólo para la permanencia, sino también para el ingreso a la universidad, especialmente de las mujeres que han sido madres a muy temprana edad. Queda entonces la pregunta: ¿el escaso número de estudiantes madres encontrados es porque no tuvieron la posibilidad de presentarse a la universidad o porque han abandonado sus estudios? Aspecto último que se ratifica en dos estudiantes de Preescolar, a las que después de haber respondido la encuesta, no fue posible entrevistarlas porque cancelaron semestre, por la maternidad.

Un aspecto que cobra relevancia es que estas personas desaparecen del registro, porque no se indagan las causas por las cuales abandonan; o cuando lo hacen se registran por factores económicos o académicos, pero nunca aparece la maternidad como causa de deserción. De esto podrían dar cuenta las familias de las jóvenes, puesto que asumir un nuevo integrante se convierte en una carga económica que se suma a las que ya tienen: estudio de la hija y crianza del nieto. Cuando la economía decrece, las familias no podrían asumir ambas responsabilidades, lo primero que se sacrifica es la educación, por tanto, las familias prefieren que sus hijas se retiren de la universidad, puesto que no pueden renunciar a sus hijos.

La resolución del dilema del embarazo inesperado asumiendo la maternidad, responde a las creencias religiosas arraigadas, al amor que sentían por sus parejas, pero sobre todo al apoyo absoluto de sus familias (padres, madres, abuelas, hermanos). La aceptación de su condición maternal como algo "más natural, menos estigmatizante", también ha estado acompañado del imperativo de "continuar sus estudios". Ambos proyectos, serán la prioridad de ahí en adelante, pues sus familias se encargan del cuidado, crianza de sus hijos y manutención de ambos, siempre y cuando ellas sigan estudiando. Estudiar y maternar son entonces dos funciones que se adhieren a su condición juvenil y se vuelven "su centro". Estas prácticas, acompañadas de discursos, dejan entrever que si bien estas jóvenes madres ya no piensan sólo en ellas, el cuidado de su hijo no significa abandonar sus proyectos de vida, por el contrario, la maternidad les permite focalizar sus esfuerzos, para que ellas no abandonen la universidad. 


\section{Referencias}

Barrero Rivera, F., C. Barrero Espinosa, H. Borja Cely y M. Montaño Sinisterra (2015), "Factores de riesgo asociados a la deserción estudiantil universitaria en programas de pregrado de la Universidad de San Buenaventura, Bogotá (2009-2013)", Revista Academia y Virtualidad, 8, (2), pp. 60-72.

Cimino, J., B. Durán, R. Herbage, M. Palma y J. Roa (2014), "Ser madre y estudiante universitaria en la Universidad de Santiago de Chile: un estudio exploratorio acerca de las implicancias psicosociales en el enfrentamiento de ambos roles", Revista de estudios cualitativos USACH, 1(1), pp. 23-39, recuperado de <http://www.rec-usach.cl/ ojs/index.php/rec/article/view/4/pdf_13>.

Estupiñán, M. R. y L. Rodríguez (2009), "Aspectos psicosociales en universitarias embarazadas", Revista Salud Pública, 11 (6), pp. 988-998.

Estupiñán, M. R. y D. Vela (2012), "Calidad de vida de madres adolescentes estudiantes universitarias", Revista Colombiana de Psiquiatría, 41(3), julio-septiembre, pp. 536-549.

Galeano, E. (2007), Estrategias de investigación social cualitativa. El giro en la mirada, Medellín, Colombia, La carreta editores.

García, V., M. Pérez y R. Martínez (2014), "Aproximación a la participación de los abuelos y abuelas en la educación de sus nietos y nietas", International Fournal of Developmental and Educational Psychology, 1(1), pp. 571-579, <http:// www.redalyc.org/pdf/3498/349851780058.pdf>.

González, D. (2017), "Experiencias emocionales y sentidos de lo político en las prácticas cotidianas de las familias", Tesis de Doctorado, Colombia, CINDE-Universidad de Manizales.

González, D. y A. M. Molina (2016), "Reflexiones sobre jóvenes universitarios que son madres o padres", en $I I$ Bienal Iberoamericana de Infancias y Juventudes, Colombia, Universidad de Manizales.

Hernández, K. y E. Orozco (2011), "Embarazo en estudiantes de carreras universitarias", Dictamen Libre, 8(8), enero-junio, pp. 68-72.
Ministerio de Educación Nacional de Colombia (2013), Acuerdo nacional para disminuir la deserción en educación superior politica y estrategias para incentivar la permanencia y graduación en educación superior 2013-2014, http://www. mineducacion.gov.co/sistemasdeinformacion/1735/ articles-254702_archivo_pdf_politicas_estadisticas.pdf.

Ministerio de Educación Nacional de Colombia (2009), Deserción estudiantil en la educación superior colombiana Metodología de seguimiento, diagnóstico y elementos para su prevención, Bogotá, Viceministerio de Educación Superior.

Noriega, C. (2015), "Percepción de los abuelos de la relación con sus nietos: valores, estilos educativos, fortalezas y bienestar", Tesis de Doctorado, Madrid, Universidad Complutense de Madrid.

Piratoba H., B. N., O. Ovidio y O. Barbosa Ch. (2013), "Factores de deserción de los estudiantes en la facultad de enfermería de la universidad de ciencias aplicadas y ambientales U.D.C.A., durante el periodo: 2009-2010-I 2011 ", Rev. U.D.C.A. Act. \& Div. Cient., 16(2), pp. 553562, julio-diciembre.

Profamilia (2015a) Ministerio de Salud y Protección Social y la Asociación Probienestar de la Familia Colombiana, con el apoyo de la Agencia de los Estados Unidos para el Desarrollo Internacional (USAID), el Fondo de Población de Naciones Unidas (UNFPA), ONU Mujeres y The Open Society Foundation. ISBN 978-958-540109-9 Recuperado en: <https://profamilia.org.co/wpcontent/uploads/2018/12/ENDS-TOMO-I.pdf $>$.

Profamilia (2015b) Ministerio de Salud y Protección Social y la Asociación Probienestar de la Familia Colombiana, con el apoyo de la Agencia de los Estados Unidos para el Desarrollo Internacional (USAID), el Fondo de Población de Naciones Unidas (UNFPA), ONU Mujeres y The Open Society Foundation. ISBN 978-958-540109-9 Recuperado en: <https://profamilia.org.co/wpcontent/uploads/2018/12/ENDS-TOMO-II.pdf>.

Profamilia (2011), Encuesta Nacional de Demografia y Salud (2010), <http://profamilia.org.co/docs/ENDS\%20 2010.pdf $>$. 


\section{Agradecimientos}

Este proyecto fue posible gracias al apoyo del CODEI (centro de costos 206001085), el respaldo del Grupo de investigación Observatos y la Facultad de Educación y Ciencias Sociales, Tecnológico de Antioquia IU. Gracias a los expertos Leonardo Ceballos Urrego, Docente de Planta de la Facultad de Ingenierías, TA-IU y Roberto Antonio Suárez Urrego, Magister en Ingeniería de Sistemas, Docente de Cátedra, TA-IU. A los estudiantes, padres y madres que generosamente ofrecieron su experiencia y su intimidad. A los estudiantes del semillero de investigación: En Familia Texto y Contexto del Tecnológico de Antioquia IU.

\section{Cómo citar este artículo:}

González-Bedoya, Diana-María y Ana-María Molina-Osorio (2020), “Condiciones socioeconómicas y afectivas de jóvenes universitarias madres de familia”, Revista Iberoamericana de Educación Superior (RIES), vol. XI, núm. 31, pp. 179-198, DoI: https://doi.org/10.22201/ iisue.20072872e.2020.31.713 [Consulta: fecha de última consulta]. 